\title{
26 Research Soure \\ Prevalence of Multidrug Resistant Tuberculosis \\ (MDR-TB) in East Africa: a Systematic Review and Meta- Analysis
}

Kindu Alem ( $\sim$ kindualem@wldu.edu.et)

Woldia University

Research Article

Keywords: Prevalence, Multidrug resistant, Tuberculosis, East Africa

Posted Date: September 13th, 2021

DOI: https://doi.org/10.21203/rs.3.rs-731476/v1

License: (c) (i) This work is licensed under a Creative Commons Attribution 4.0 International License.

Read Full License 


\section{Abstract}

Background: The rate of multidrug resistant tuberculosis is increasing at an alarming rate throughout the world. It is becoming an emerging public health problem in East Africa. Prevalence of MDR-TB among TB positive individuals in the region has not been synthesized. Determining the pooled prevalence of MDRTB among newly diagnosed and previously treated TB cases in East Africa is the main objective of this review.

Methods: In this systematic review and meta-analysis, the researcher searched six electronic databases: Google scholar, PubMed, EMBASE, Scopus, Science direct and Web of Science. Funnel plot symmetry visualization confirmed by Egger's regression asymmetry test and Begg rank correlation methods was used to assess publication bias. The pooled prevalence estimate was calculated using Der Simonian and Laird's random Effects model. A total of 16 articles published in East Africa from 2007 and 2019 were included in this study. STATA software (version 14, Texas, USA) was used for analysis.

Results: Out of 1025 articles identified citations, a total of 16 articles published in East Africa from 2007 and 2019 were included in this meta-analysis. The pooled prevalence of MDR-TB among newly diagnosed TB cases and previously treated TB patients to be $4 \%(95 \% \mathrm{Cl}=2-5 \%)$ and $21 \%(95 \% \mathrm{Cl}: 14-28 \%)$, respectively. Living conditions, lifestyles (smoking, alcohol use, and drug abuse), previous medical history, diabetes history and HIV infection risk factors contribute to higher prevalence of MDR-TB in East Africa.

Conclusion: An early diagnosis of tuberculosis and rapid detection of drug resistant Mycobacterium tuberculosis is a serious concern to identify patients who are not responding to the standard treatment and to avoid spreading of resistant strains. It is also very essential to strengthen tuberculosis control and improved monitoring of chemotherapy.

\section{Introduction}

Tuberculosis (TB) disease, caused by the Mycobacterium tuberculosis ( $M$. tuberculosis), is the main cause of death. It is killing about 2 million people each year globally and nearly half million new cases of MDR-TB emerges every year[1]. TB is ranked as the second leading cause of death from contagious disease worldwide [2]. Countries such as Russia, China and India alone accounted $47 \%$ of the global burden. Different studies carried out in many countries have shown the MDR rate is much higher in previously treated TB patients than in new TB patients [3]. The maximum TB mortality and morbidity occurs in middle and low income countries like East African countries [4]. High mortality of the TB disease was predominantly observed in human immunodeficiency virus (HIV) [5]. Currently, East Africa countries such as Ethiopia, Rwanda, Kenya, Tanzania and Uganda are among the 30 high MDR-TB burden countries. According to Gobena et al. [6], Ethiopia is one of the high burden countries with regards to TB, TB/ HIV, and MDR-TB. According to the 2016 report, $89.7 \%$ of the global incident cases of MDR-TB 
were accounted in 30 high MDR-TB burden countries. Among the 30 high burden TB countries ranked in the world, Kenya has fifth highest burden in Africa [5, 6].

The emergence of MDR-TB causes a considerable risk to TB control programs worldwide [7]. Co-infection multidrug-resistant tuberculosis (MDR-TB) did not get key attention until recently in East Africa, where the TB prevalence and risk factors are highest [8]. MDR-TB, even though being nearly $100 \%$ treatable, it is one of the major community health problems that is most-frequently the root cause of death among adults [9]. One-third of the world's population is infected with TB. The presence of the drug resistant gene in $M$. tuberculosis is the major confront of controlling TB [10]. Multidrug-resistant (MDR) (resistance to at least both to first-line anti-TB drugs such as isoniazid and rifampicin) TB occurred among $3.6 \%$ and $18 \%$ of new and previously treated TB cases, respectively (5.6\% among all cases) [4]. The main challenge in the treatment and control of tuberculosis is a high burden of MDR-TB globally [11]. Treatment of MDR-TB requires long time with a combination of second-line anti-TB drugs; most of them are less effective, has a considerable rate of adverse effects, and more expensive than first-line drugs [12].

Significant attention is not given to MDR-TB in East Africa and it has been ignored until recently in this region. Even if there are some studies about the prevalence of MDR-TB in the region, only little is known about the associated risk factors to MDR-TB in East Africa. Some studies in the region indicated that low socioeconomic status, history of anti-TB treatment, the presence of HIV infection, sex, history of diabetes mellitus, alcohol use and malnutrition were the hypothesized risk factors associated with the expansion of MDR-TB in the region $[13,14]$. A study done in Tanzania showed that risk factors associated with MDR-TB were previous history of treatment with first line anti-TB $(\mathrm{OR}=3.3,95 \% \mathrm{Cl} 1.7-6.3)$, smoking (OR $=1.9,95 \% \mathrm{Cl} 1.0-3.5)$, contact with TB case $(\mathrm{OR}=2.7,95 \% \mathrm{Cl} 1.4-5.1)$ and history of TB [15]. Similarly, a study done in Ethiopia revealed that a history of previous treatment $(\mathrm{AOR}=21 ; 95 \% \mathrm{Cl}$ : 17.8-28) and being HIV infected (AOR $=3.1 ; 95 \% \mathrm{Cl}: 1.02-9.4$ ) were found to be associated risk factors of MDR-TB [8]. There are a lot of published studies done on MDR-TB in different part of East Africa. However, there were no previous studies that estimate the pooled prevalence of MDR-TB among TB positive individuals in East Africa. This might be due to poor laboratory facilities, outdated databases and poor surveillance mechanisms and reporting procedures. Therefore, the researcher, aimed to conduct a systematic review and meta-analysis to assess the pooled prevalence of MDR-TB among TB positive individuals in East Africa. Thus, this review designed to provide a current and comprehensive pooled prevalence of MDR-TB in East Africa. Findings from this work can inform intervention strategies and future MDR-TB monitoring.

\section{Methods}

This review was conducted literature search of articles published between 2007 and 2019 containing information on MDR-TB prevalence. Search engines, electronic bibliographic databases and libraries: Google scholar, PubMed, EMBASE, Scopus, Science direct and Web of Science were used to retrieve articles published within the study period.

\section{Inclusion and exclusion criteria}


In this review, studies reporting on MDR in new TB cases and on MDR in previously treated TB cases were included in the final analysis. The review included all eligible studies published in English from 2007 to 2019 in East Africa. Extraction of eligible review for this study used the following information: first author's name; study area, year of publication, number of individuals screened for new cases of MDR-TB, number of positive for new cases of MDR-TB, the number of previously treated MDR-TB, and a number of previously treated MDR-TB who are positive. Because of any of the following reasons, studies were excluded from the analysis: duplicate publication of the same study, articles available only in abstract form, case reports, anonymous reports, studies with data unrelated to MDR-TB, studies conducted outside of East Africa and studies without adequate data.

\section{Data extraction}

For data rescue, the author developed an extraction format to extract the following information: Author(s), year of publication, study period, study area, sample size, new cases of MDR-TB and previously treated MDR-TB. The author examined the quality of the studies by using a set of criteria such as: quality of reported data and appropriateness of the method used for MDR-TB detection among newly diagnosed and previously treated TB cases.

\section{Data analysis}

The researcher used STATA statistical software (version 14, Texas, USA) to analysis the data. To assess the descriptions of original studies forest plots were used in this study. Funnel plot symmetry visualization followed by Egger's regression asymmetry test and Begg rank correlation methods were used to identify the presence of publication bias. By using Der Simonian and Laird's random effects model, point prevalence estimate of each study with a $95 \%$ confidence interval was used to estimate pooled prevalence.

\section{Results}

A total of 1025 articles were recovered from Google scholar, PubMed, EMBASE, Scopus, Science direct, and Web of Science. The process of article selection is indicated in Fig. 1. Of these, 271 articles were excluded due to duplication. Out of these, 665 research articles which don't match with this study objective were excluded after reviewing their title and abstracts. Then the remaining 89 articles were identified for full text review. Out of the 89 articles reviewed in full text, 16 articles were retained for final meta-analysis based on the inclusion-exclusion criteria and quality assessment and 73 studies were removed prior to analysis for different reasons such as full text unavailability, overlapped studies, case reports and articles with lack of sufficient data.

\section{Publication bias and Heterogeneity}

As indicated in Figs. 2 and 4, funnel plot symmetry visual inspection was used to determine the occurrence of publication bias and the result showed absence of publication bias. In this review, absence 
of publication bias was statistically confirmed by Egger's weighted regression test (bias coefficient $(B)=$ 4.7, -2.18-5.46; $P=0.37)$ and (bias coefficient $(B)=3.4,(95 \% \mathrm{Cl}=-3.01-1.7 ; \mathrm{P}=0.54)$ for MDR-TB among newly diagnosed cases and among previously treated cases, respectively. In this study heterogeneity analysis for newly diagnosed and previously treated MDR-TB showed that the occurrence of high variance among studies $\left(I^{2}=94.7 \%, P=0.000\right)$ and $\left(I^{2}=99.1 \%, P=0.000\right)$, respectively, which was statistically significant.

\section{Pooled prevalence estimate}

In this meta-analysis 11720 TB patients were included and 455 were developed new MDR-TB. Out of 9490 previously treated MDR-TB, 1842 were positive for MDR-TB, respectively (Table 1). The pooled prevalence of MDR-TB among newly diagnosed TB cases was $4 \%(95 \% \mathrm{Cl}: 2-5 \%) ; I^{2}=94.7 \%, \mathrm{P}=0.000$ (Fig. 3). Among newly diagnosed MDR-TB cases, the highest prevalence was reported to be $20 \%$ by Sabeel et al. [16]. The overall prevalence of MDR-TB among previously treated TB cases was $21 \%(95 \% \mathrm{Cl}$ : $14-28 \%) ; I^{2}=99.1 \%, P=0.000$ (Fig. 5). The prevalence of MDR-TB among previously treated TB cases of each of the studies included in this systematic review ranges from $1 \%((95 \% \mathrm{Cl}:-0.00-1.00)$ by Range et al. [17] to $91 \%(95 \% \mathrm{Cl}: 81-101)$ by Okethwangu et al. [18]. The researcher found that the pooled burden of MDR-TB among newly diagnosed and previously treated TB cases varied considerably from country to country in the study region. 
Table 1

General characteristics of studies included in this meta-analysis in East Africa, 2007 to 2019.

\begin{tabular}{|c|c|c|c|c|c|}
\hline Author (s) & $\begin{array}{l}\text { Study } \\
\text { area }\end{array}$ & $\begin{array}{l}\text { Number of } \\
\text { individuals } \\
\text { screened for new } \\
\text { cases of MDR-TB }\end{array}$ & $\begin{array}{l}\text { Number of } \\
\text { positive } \\
\text { for New cases } \\
\text { of MDR-TB }\end{array}$ & $\begin{array}{l}\text { Number of } \\
\text { Previously } \\
\text { treated } \\
\text { MDR-TB }\end{array}$ & $\begin{array}{l}\text { Number } \\
\text { of } \\
\text { previously } \\
\text { treated } \\
\text { MDR-TB } \\
\text { who are } \\
\text { positive }\end{array}$ \\
\hline Admassu,2011[19] & Ethiopia & 410 & 19 & 150 & 74 \\
\hline $\begin{array}{l}\text { Mekonnen et al., } \\
2015 \text { [20] }\end{array}$ & Ethiopia & 124 & 2 & 124 & 5 \\
\hline $\begin{array}{l}\text { Brhane et al.,2017 } \\
\text { [21] }\end{array}$ & Ethiopia & 105 & 3 & 105 & 7 \\
\hline $\begin{array}{l}\text { Biresaw et al., } \\
2018 \text { [22] }\end{array}$ & Ethiopia & 381 & 0 & 381 & 7 \\
\hline $\begin{array}{l}\text { Girum et al., } 2018 \\
\text { [23] }\end{array}$ & Ethiopia & 7461 & 163 & 7461 & 1572 \\
\hline $\begin{array}{l}\text { Kerubo et al., } 2016 \\
\text { [24] }\end{array}$ & Kenya & 160 & 7 & 24 & 2 \\
\hline $\begin{array}{l}\text { Huerga et al., } 2017 \\
\text { [25] }\end{array}$ & Kenya & 169 & 4 & 169 & 24 \\
\hline $\begin{array}{l}\text { Umubyeyi et al., } \\
2007 \text { [26] }\end{array}$ & Rwanda & 616 & 24 & 85 & 8 \\
\hline $\begin{array}{l}\text { Eldin et al., } 2011 . \\
\text { [27] }\end{array}$ & Sudan & 43 & 8 & 71 & 17 \\
\hline $\begin{array}{l}\text { Sabeel et al., } 2017 \\
\text { [16] }\end{array}$ & Sudan & 75 & 15 & 15 & 4 \\
\hline $\begin{array}{l}\text { Eldirdery et al., } \\
2017 \text { [28] }\end{array}$ & Sudan & 88 & 4 & 21 & 7 \\
\hline $\begin{array}{l}\text { Chonde et al., } \\
2010 \text { [29] }\end{array}$ & Tanzania & 1019 & 11 & 148 & 40 \\
\hline $\begin{array}{l}\text { Range et al., } 2012 \\
{[17]}\end{array}$ & Tanzania & 503 & 9 & 503 & 3 \\
\hline Lukoye et al., 2011 & Uganda & 533 & 5 & 60 & 7 \\
\hline Lukoye, 2013 [30] & Uganda & 1397 & 178 & 140 & 35 \\
\hline $\begin{array}{l}\text { Okethwangu et al., } \\
2019 \text { [18] }\end{array}$ & Uganda & 33 & 3 & 33 & 30 \\
\hline Total & & 11720 & 455 & 9490 & 1842 \\
\hline
\end{tabular}




\section{Discussion}

Multidrug resistant tuberculosis is a major global health problem. TB continues to be a great health treat in developing countries and is compounded by the high burden of MDR-TB [31]. There is still a serious knowledge gap about multidrug resistant tuberculosis in East Africa countries. Therefore, in order to find out the current circumstance of MDR-TB in the region, recent and evidence based studies are significantly required. Thus, this systematic review and meta-analysis addressed the prevalence of new MDR-TB and previously treated MDR-TB using 16 selected studies conducted from 2007 to 2019 in East Africa. In this review and meta-analysis, the prevalence of newly diagnosed MDR-TB ranged from 1\% (95\%Cl: 0.0-2\%) to $20 \%(95 \% \mathrm{Cl}: 11-29 \%)$ with a pooled prevalence of $4 \%(95 \% \mathrm{Cl}: 2-5 \%)$. The results of this metaanalysis showed that the pooled prevalence of newly diagnosed MDR-TB was somewhat higher than a previous meta-analysis report by Eshetie et al. [32] where $2 \%(95 \% \mathrm{Cl} 1-2 \%)$ of newly diagnosed TB patients have MDR-TB. According to the results of this meta-analysis, the prevalence of MDR-TB among previously treated cases ranged from $1 \%((95 \% \mathrm{Cl}:-0.00-1.00)$ to $91 \%(95 \% \mathrm{Cl}: 81-101)$ with a pooled prevalence of $21 \%(95 \% \mathrm{Cl}: 14-28 \%)$. Similarly, the same study done in Ethiopia [32] showed that the pooled prevalence of MDR-TB among previously treated cases was $15 \%(95 \% \mathrm{Cl} 12 \%-17 \%)$ which was lower than the present study. In this review, the researcher found that the level of MDR-TB were higher in East Africa than reported globally for both new and previously treated MDR-TB. This study result showed that MDR-TB estimates as almost six times higher as compared to the global average reported by WHO for both new and previously treated (21\% vs $3.6 \%)$ TB positive patients [33]. According to this metaanalysis, the pooled prevalence of MDR-TB was higher than the pooled prevalence of MDR-TB with a previous meta-analysis report that was conducted in Ethiopia [23]. According to the WHO report of 2015, globally the prevalence of MDR-TB of new cases and previously treated cases of TB was $3.5 \%$ and $20.5 \%$, respectively, while Sub-Saharan Africa countries contributing the highest proportion and these levels in recent years have remained unchanged $[34,35]$. The main reasons behind the appearance of MDR-TB globally are multi-factor and are related to living conditions [36], life style [15], previous medical history [37, 38], diabetes history [39, 40], HIV infection [41], and education level [37].

Poor and crowded living conditions of a family might make easy the spread of TB. Thus, these lower socioeconomic family groups should get the highest concern for MDR-TB prevention efforts [42]. Patients that live in a household with more than one room were five times at lower risk of having MDR-TB than those living in a household with only one room [8]. This might be as a result of high risk of getting resistant strains from infected people in crowded places. Different lifestyles such as alcohol abuse, smoking, drugs use, etc. are the major risk factors associated with the development of MDR-TB. Cigarette smokers were more likely to be infected with MDR-TB infection and have less chance to be cured. Male cigarette smokers were more likely to be infected with MDR-TB and susceptible compared than females. This might be due to that men are predominantly drink alcohol, smoke and consume the drug compared to women $[6,43-45]$.

The longer exposure of a patient to anti-tuberculosis drugs was also associated with the development of MDR-TB. Patients under multiple situation of anti-tuberculosis treatment might create greater antibiotic 
resistance with the consequent development of MDR-TB and XDR-TB cases. Previous TB disease and chemotherapy are the most important risk factors associated with MDR-TB [37, 38, 46]. The global diabetes mellitus (DM) epidemic creates a serious bottleneck to the TB control program [47]. Individuals with diabetes, as compared to non-diabetic controls, were two-to three-folds more likely to develop TB. Weakened immunity in diabetic patients is thought to contribute to the development of latent TB infection to active cases $[39,40]$.

A study done in Ethiopia revealed that human immunodeficiency virus (HIV) infection was identified as a significant factor associated for MDR-TB [22]. Moreover, individuals living with HIV might also be more likely to be exposed to MDR-TB because of longer hospitalization in settings with low infection control. Drug malabsorption in HIV infected people can also lead to drug resistance and has been shown to result in treatment failure [48]. In one study conducted by Al-Darraji et al.[49] revealed that there was $20 \%$ higher occurrence of MDR-TB among HIV-positive persons than those HIV-negative persons. Patients with low education level have been associated with the development of MDR-TB. [37]. A study conducted by Ronaidi et al. [50] showed that the number of MDR-TB infected patients is significantly higher among the lower education group compared to the higher education group. It has been reported that the higher prevalence of pulmonary TB with unsuccessful treatment outcome was observed in patients who had a lower education level [51]. However, studies conducted in Ethiopia and Sudan showed that educational status was not significantly associated with MDR-TB [52-54].

\section{Limitations}

This review had some limitations. Out of 11 East Africa countries, only 6 countries had done studies that fulfilled the inclusion criteria. This review has been summarized the findings of 16 published articles about the prevalence and the associated risk factors of MDR-TB in East Africa. The findings of this review are limited because of a small number of study countries, small number of published articles, and small sample size of study samples conducted on the prevalence of MDR-TB. However, the findings of this review give reliable results on MDR-TB in East Africa.

\section{Conclusions}

MDR-TB is a global public health problem, especially in East Africa. Most of the studies in this review showed that the pooled prevalence of MDR-TB in TB infected individuals is higher by far in the study area than results reported in previous studies. The majority of the studies in this review indicated that, living conditions, lifestyles (smoking, alcohol use, and drug abuse), previous medical history, diabetes history and HIV infection risk factors contribute to higher prevalence of MDR-TB in East Africa. Effective health promotion activities about TB should be given a special attention. TB control program to improve the patient's dependence to anti-TB drugs and creation of awareness about the mode of transmission of TB for people living in a household with only one room is mandatory. Well-organized measures also need to be implemented to encourage early diagnosis of MDR-TB and treatment before complication. 


\section{Abbreviations}

Cl: Confidence interval; HIV: Human immunodeficiency virus; MDR-TB: Multidrug-resistant tuberculosis; OR: Odds ratio; TB: Tuberculosis; WHO: World Health Organization; MT: Mycobacterium tuberculosis

\section{Declarations}

\section{Competing interests}

The author declares that he has no competing interests.

\section{Author' contributions}

The author had a contribution of conceptualization of the idea, literature search, identified on studies for inclusion, extracted the data, data synthesis and analysis, wrote the initial draft, reviewed the final draft before submission, and read and approved the final manuscript.

\section{Acknowledgments}

All authors who had investigated and provide information about the prevalence of MDR-TB, and associated risk factors.

\section{Data availability}

All data underlying the results are available as part of the articles and no additional source data are required.

Ethics approval and consent to participate

Not applicable

\section{Consent for publication}

Not applicable.

\section{References}

1. Phelan J, De Sessions PF, Tientcheu L, Perdigao J, Machado D, Hasan R, Hasan Z, Bergval IL, Anthony R, McNerney R: Methylation in Mycobacterium tuberculosis is lineage specific with associated mutations present globally. Scientific reports 2018, 8(1):1-7.

2. Biadglegne F, Mulu A, Rodloff AC, Sack U: Diagnostic performance of the Xpert MTB/RIF assay for tuberculous lymphadenitis on fine needle aspirates from Ethiopia. Tuberculosis 2014, 94(5):502-505.

3. Floyd K, Glaziou P, Zumla A, Raviglione M: The global tuberculosis epidemic and progress in care, prevention, and research: an overview in year 3 of the End TB era. The Lancet Respiratory 
Medicine 2018, 6(4):299-314.

4. MacNeil A, Glaziou P, Sismanidis C, Maloney S, Floyd K: Global epidemiology of tuberculosis and progress toward achieving global targets-2017. Morbidity and Mortality Weekly Report 2019, 68(11):263.

5. Organization WH: Drug-resistant TB: surveillance and response: supplement to global tuberculosis report 2014. In.: World Health Organization; 2014.

6. Gobena D, Ameya G, Haile K, Abreha G, Worku Y, Debela T: Predictor of multidrug resistant tuberculosis in southwestern part of Ethiopia: a case control study. Annals of clinical microbiology and antimicrobials 2018, 17(1):1-7.

7. Shen X, DeRiemer K, Yuan Z-A, Shen M, Xia Z, Gui X, Wang L, Gao Q, Mei J: Drug-resistant tuberculosis in Shanghai, China, 2000-2006: prevalence, trends and risk factors. The International Journal of Tuberculosis and Lung Disease 2009, 13(2):253-259.

8. Workicho A, Kassahun W, Alemseged F: Risk factors for multidrug-resistant tuberculosis among tuberculosis patients: a case-control study. Infection and drug resistance 2017, 10:91.

9. Stosic M, Vukovic D, Babic D, Antonijevic G, Foley KL, Vujcic I, Grujicic SS: Risk factors for multidrugresistant tuberculosis among tuberculosis patients in Serbia: a case-control study. BMC public health 2018, 18(1):1-8.

10. Jain A, Dixit P: Multidrug resistant to extensively drug resistant tuberculosis: what is next? Journal of biosciences 2008, 33(4):605-616.

11. Migliori GB, Tiberi S, Zumla A, Petersen E, Chakaya JM, Wejse C, Torrico MM, Duarte R, Alffenaar JW, Schaaf HS: MDR/XDR-TB management of patients and contacts: Challenges facing the new decade. The 2020 clinical update by the Global Tuberculosis Network. International Journal of Infectious Diseases 2020, 92:S15-S25.

12. Seung KJ, Keshavjee S, Rich ML: Multidrug-resistant tuberculosis and extensively drug-resistant tuberculosis. Cold Spring Harbor perspectives in medicine 2015, 5(9):a017863.

13. Ambaye GY, Tsegaye GW: Factors Associated with Multi-Drug Resistant Tuberculosis among TB Patients in Selected Treatment Centers of Amhara Region: A Case-Control Study. Ethiopian journal of health sciences 2021, 31(1).

14. Gyamfi-Gyimah C: Predictors for Multidrug-Resistant Tuberculosis among Tuberculosis Patients, Brong Ahafo Region, Ghana, 2019. University of Ghana; 2019.

15. Lema NA, Mbelele PM, Majigo M, Abade A, Matee MI: Risk factors associated with multidrug resistant tuberculosis among patients referred to Kibong'oto Infectious Disease Hospital in northern Tanzania. Tanzania Journal of Health Research 2016, 18(4).

16. Sabeel S, Salih MA, Ali M, El-Zaki S-E, Abuzeid N, Elgadi ZAM, Altayb HN, Elegail A, Ibrahim NY, Elamin BK: Phenotypic and genotypic analysis of multidrug-resistant Mycobacterium tuberculosis isolates from Sudanese patients. Tuberculosis research and treatment 2017, 2017.

17. Range N, Friis H, Mfaume S, Magnussen P, Changalucha J, Kilale A, Mugomela A, Andersen AB: Antituberculosis drug resistance pattern among pulmonary tuberculosis patients with or without HIV 
infection in Mwanza, Tanzania. Tanzania Journal of Health Research 2012, 14(4).

18. Okethwangu D, Birungi D, Biribawa C, Kwesiga B, Turyahabwe S, Ario AR, Zhu B-P: Multidrug-resistant tuberculosis outbreak associated with poor treatment adherence and delayed treatment: Arua District, Uganda, 2013-2017. BMC infectious diseases 2019, 19(1):1-10.

19. Admassu DMA: Multidrug and Heteroresistant Mycobacterium. tuberculosis (comnent) 2011, 378:204.

20. Mekonnen F, Tessema B, Moges F, Gelaw A, Eshetie S, Kumera G: Multidrug resistant tuberculosis: prevalence and risk factors in districts of metema and west armachiho, Northwest Ethiopia. $B M C$ infectious diseases 2015, 15(1):1-6.

21. Brhane $M$, Kebede A, Petros $Y$ : Molecular detection of multidrug-resistant tuberculosis among smearpositive pulmonary tuberculosis patients in Jigjiga town, Ethiopia. Infection and drug resistance $2017,10: 75$.

22. Demile B, Zenebu A, Shewaye H, Xia S, Guadie A: Risk factors associated with multidrug-resistant tuberculosis (MDR-TB) in a tertiary armed force referral and teaching hospital, Ethiopia. BMC infectious diseases 2018, 18(1):1-10.

23. Girum T, Muktar E, Lentiro K, Wondiye H, Shewangizaw M: Epidemiology of multidrug-resistant tuberculosis (MDR-TB) in Ethiopia: a systematic review and meta-analysis of the prevalence, determinants and treatment outcome. Tropical diseases, travel medicine and vaccines 2018, 4(1):112.

24. Kerubo G, Amukoye E, Niemann S, Kariuki S: Drug susceptibility profiles of pulmonary Mycobacterium tuberculosis isolates from patients in informal urban settlements in Nairobi, Kenya. BMC infectious diseases 2016, 16(1):1-7.

25. Huerga H, Bastard M, Kamene M, Wanjala S, Arnold A, Oucho N, Chikwanha I, Varaine F: Outcomes from the first multidrug-resistant tuberculosis programme in Kenya. The International Journal of Tuberculosis and Lung Disease 2017, 21(3):314-319.

26. Umubyeyi AN, Vandebriel G, Gasana M, Basinga P, Zawadi J, Gatabazi J, Pauwels P, Nzabintwali F, Nyiramasarabwe L, Fissette K: Results of a national survey on drug resistance among pulmonary tuberculosis patients in Rwanda. The International Journal of Tuberculosis and Lung Disease 2007, 11(2):189-194.

27. Eldin GSS, Fadl-Elmula I, Ali MS, Ali AB, Salih ALG, Mallard K, Bottomley C, McNerney R: Tuberculosis in Sudan: a study of Mycobacterium tuberculosis strain genotype and susceptibility to antituberculosis drugs. BMC infectious diseases 2011, 11(1):1-8.

28. Eldirdery MM, Intisar E, Mona O, Fatima A, Asrar M, Nuha Y: Prevalence of multidrug-resistant tuberculosis among smear positive pulmonary tuberculosis patients in eastern Sudan. Am J Microbiol Res 2017, 5:32-36.

29. Chonde T, Basra D, Mfinanga S, Range N, Lwilla F, Shirima R, Van Deun A, Zignol M, Cobelens F, Egwaga S: National anti-tuberculosis drug resistance study in Tanzania. The International Journal of Tuberculosis and Lung Disease 2010, 14(8):967-972. 
30. Lukoye D, Adatu F, Musisi K, Kasule GW, Were W, Odeke R, Kalamya JN, Awor A, Date A, Joloba ML: Anti-tuberculosis drug resistance among new and previously treated sputum smear-positive tuberculosis patients in Uganda: results of the first national survey. PloS one 2013, 8(8):e70763.

31. Amor YB, Nemser B, Singh A, Sankin A, Schluger N: Underreported threat of multidrug-resistant tuberculosis in Africa. Emerging infectious diseases 2008, 14(9):1345.

32. Eshetie S, Gizachew M, Dagnew M, Kumera G, Woldie H, Ambaw F, Tessema B, Moges F: Multidrug resistant tuberculosis in Ethiopian settings and its association with previous history of antituberculosis treatment: a systematic review and meta-analysis. BMC infectious diseases 2017, $17(1): 1-12$.

33. Organization WH: World Health Organization multidrug and extensively drug-resistant TB (M/XDRTB): 2010 global report on surveillance andresponse. WorldHealthOrganization, Geneva, Switzerland. In.; 2010.

34. Organization WH: World Health Organization global tuberculosis control report 2009. Global tuberculosis control 2011.

35. Migliori GB, Dheda K, Centis R, Mwaba P, Bates M, O'Grady J, Hoelscher M, Zumla A: Review of multidrug-resistant and extensively drug-resistant TB: global perspectives with a focus on subSaharan Africa. Tropical Medicine \& International Health 2010, 15(9):1052-1066.

36. Chen S, Huai P, Wang X, Zhong J, Wang X, Wang K, Wang L, Jiang S, Li J, Peng Y: Risk factors for multidrug resistance among previously treated patients with tuberculosis in eastern China: a casecontrol study. International Journal of Infectious Diseases 2013, 17(12):e1116-e1120.

37. Chung-Delgado K, Guillen-Bravo S, Revilla-Montag A, Bernabe-Ortiz A: Mortality among MDR-TB cases: comparison with drug-susceptible tuberculosis and associated factors. PloS one 2015, 10(3):e0119332.

38. Abdella K, Abdissa K, Kebede W, Abebe G: Drug resistance patterns of Mycobacterium tuberculosis complex and associated factors among retreatment cases around Jimma, Southwest Ethiopia. BMC public health 2015, 15(1):1-7.

39. Alkabab YM, Al-Abdely HM, Heysell SK: Diabetes-related tuberculosis in the Middle East: an urgent need for regional research. International Journal of Infectious Diseases 2015, 40:64-70.

40. Baker MA, Harries AD, Jeon CY, Hart JE, Kapur A, Lönnroth K, Ottmani S-E, Goonesekera SD, Murray $\mathrm{MB}$ : The impact of diabetes on tuberculosis treatment outcomes: a systematic review. BMC medicine 2011, 9(1):1-15.

41. Mesfin YM, Hailemariam D, Biadglign S, Kibret KT: Association between HIV/AIDS and multi-drug resistance tuberculosis: a systematic review and meta-analysis. PloS one 2014, 9(1):e82235.

42. He GX, Wang HY, Borgdorff MW, Van Soolingen D, Van Der Werf MJ, Liu ZM, Li XZ, Guo H, Zhao YL, Varma JK: Multidrug-resistant tuberculosis, People's Republic of China, 2007-2009. Emerging infectious diseases 2011, 17(10):1831.

43. Dujaili JA, Sulaiman SAS, Awaisu A, Muttalif AR, Blebil AQ: Outcomes of tuberculosis treatment: a retrospective cohort analysis of smoking versus non-smoking patients in Penang, Malaysia. Journal 
of Public Health 2011, 19(2):183-189.

44. Ariffin F, Zubaidi AA, Yasin MM, Ishak R: Management of pulmonary tuberculosis in health clinics in the Gombak district: How are we doing so far? Malaysian family physician: the official journal of the Academy of Family Physicians of Malaysia 2015, 10(1):26.

45. Rajendran M, Zaki RA, Aghamohammadi N: Contributing risk factors towards the prevalence of multidrug-resistant tuberculosis in Malaysia: A systematic review. Tuberculosis 2020, 122:101925.

46. Pradipta IS, Forsman LD, Bruchfeld J, Hak E, Alffenaar J-W: Risk factors of multidrug-resistant tuberculosis: A global systematic review and meta-analysis. Journal of Infection 2018, 77(6):469478.

47. Lönnroth K, Roglic G, Harries AD: Improving tuberculosis prevention and care through addressing the global diabetes epidemic: from evidence to policy and practice. The lancet Diabetes \& endocrinology 2014, 2(9):730-739.

48. Ibrahim E, Baess Al, Al Messery MA: Pattern of prevalence, risk factors and treatment outcomes among Egyptian patients with multidrug resistant tuberculosis. Egyptian Journal of Chest Diseases and Tuberculosis 2017, 66(3):405-411.

49. Al-Darraji HAA, Tan C, Kamarulzaman A, Altice FL: Prevalence and correlates of latent tuberculosis infection among employees of a high security prison in Malaysia. Occupational and environmental medicine 2015, 72(6):442-447.

50. NM NNR, Mohd N, Sharina D, NH NR: Factors associated with unsuccessful treatment outcome of pulmonary tuberculosis in Kota Bharu, Kelantan. Malaysian Journal of Public Health Medicine 2011, 11(1):6-15.

51. Azura S, Hussin S, Rahman M: Drug resistance and Susceptibility of Mycobacterium tuberculosis identified at University Kebangsaan Malaysia Medical Centre. Pakistan Journal of Medical Sciences $2011,27(5)$.

52. Ali MH, Alrasheedy AA, Hassali MA, Kibuule D, Godman B: Predictors of multidrug-resistant tuberculosis (MDR-TB) in Sudan. Antibiotics 2019, 8(3):90.

53. Desissa F, Workineh T, Beyene T: Risk factors for the occurrence of multidrug-resistant tuberculosis among patients undergoing multidrug-resistant tuberculosis treatment in East Shoa, Ethiopia. BMC public health 2018, 18(1):1-6.

54. Assefa D, Seyoum B, Oljira L: Determinants of multidrug-resistant tuberculosis in Addis Ababa, Ethiopia. Infection and drug resistance 2017, 10:209.

\section{Figures}




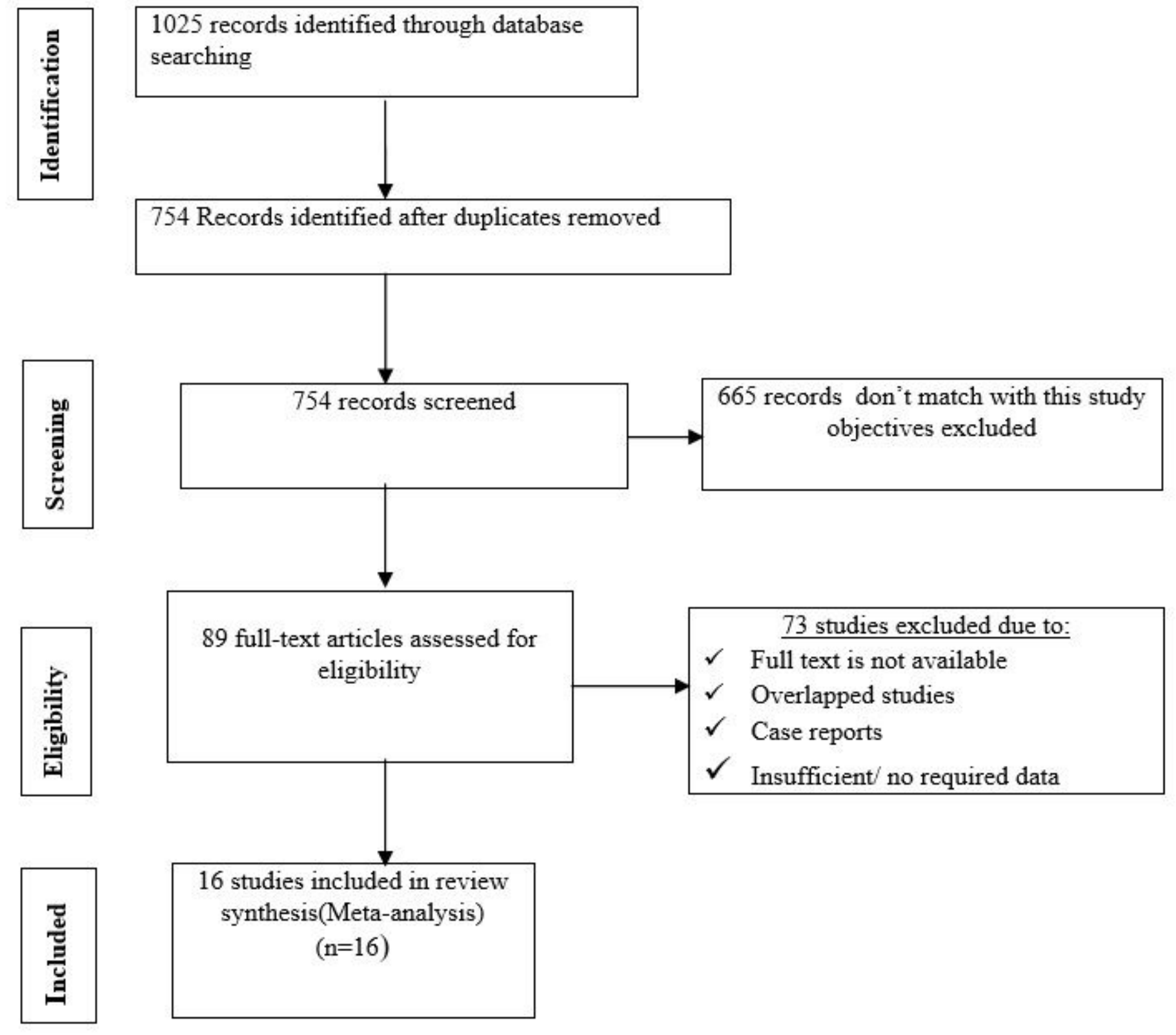

Figure 1

Flow chart diagram showing study screening and selection procedure. 


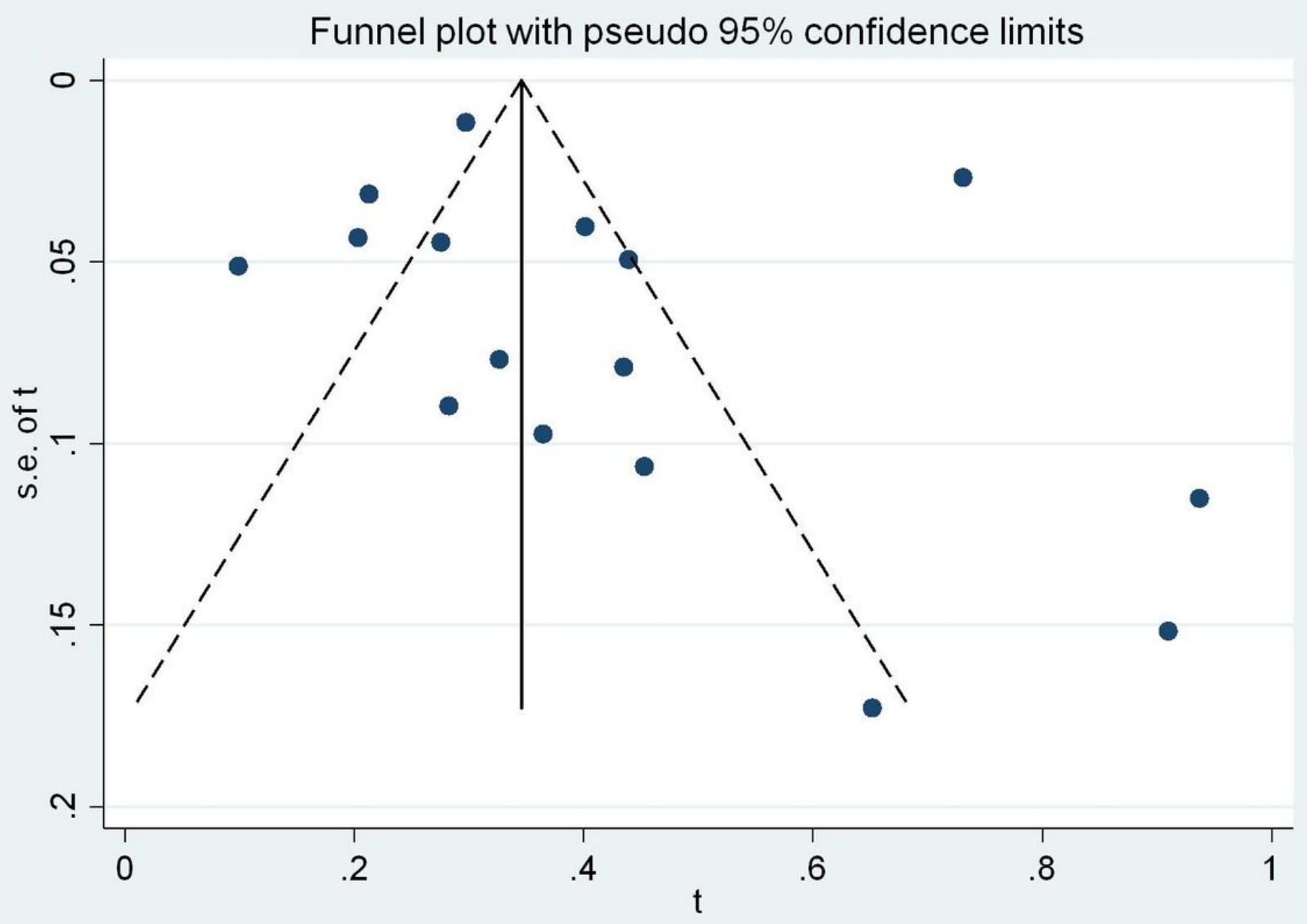

Figure 2

Meta funnel representation of prevalence estimate of MDR-TB among newly diagnosed TB cases in East Africa, 2007 to 2019. Abbreviation: $t$ : arcsine transformed prevalence estimate of MDR-TB among new diagnosed TB cases and se of $t$, standard error of $t$. 


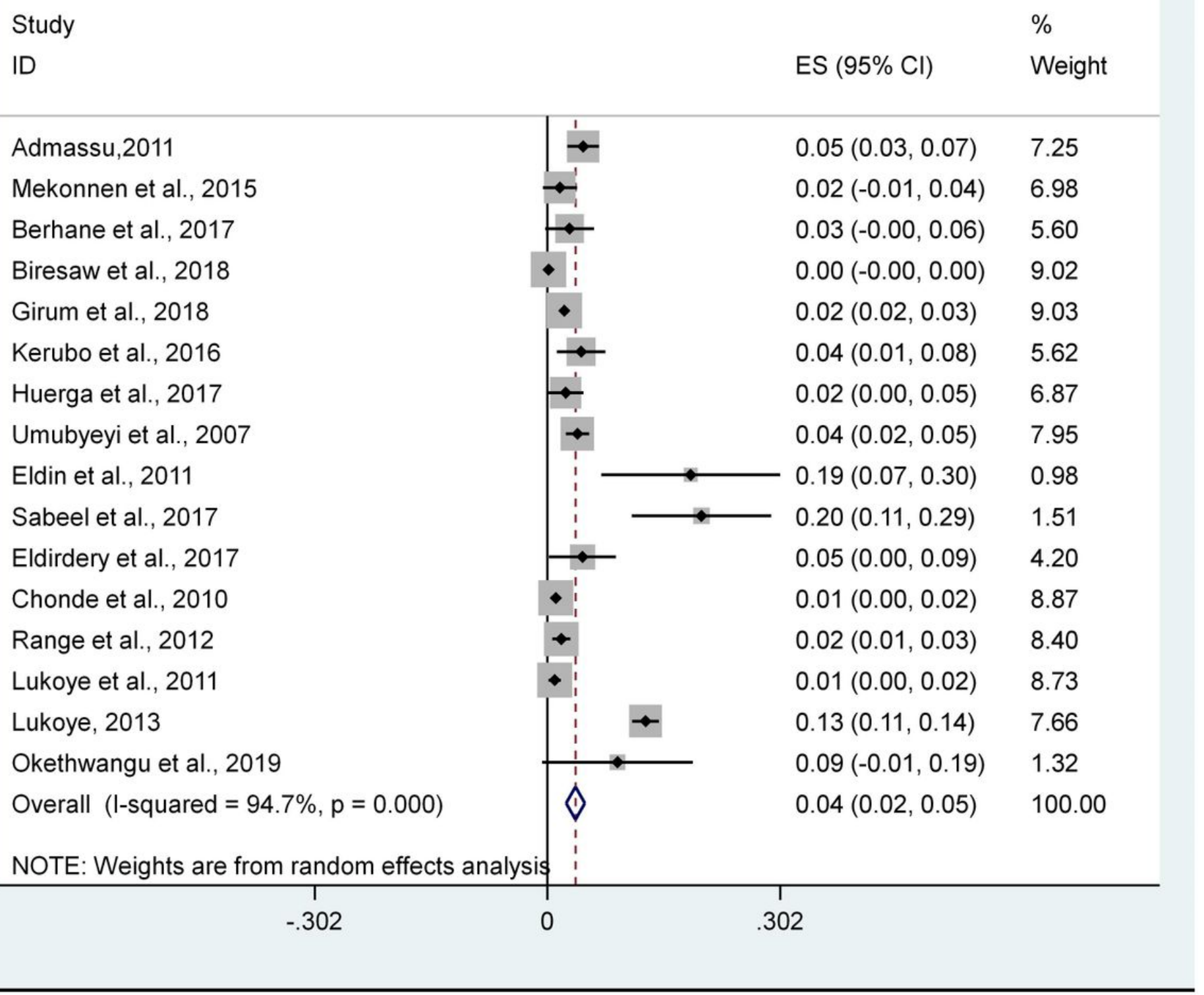

\section{Figure 3}

Forest plot showing the prevalence of MDR-TB among new diagnosed TB cases in East Africa, 2007 to 2019. Abbreviation: ES: Effect size; Cl: Confidence interval 


\section{Funnel plot with pseudo $95 \%$ confidence limits}

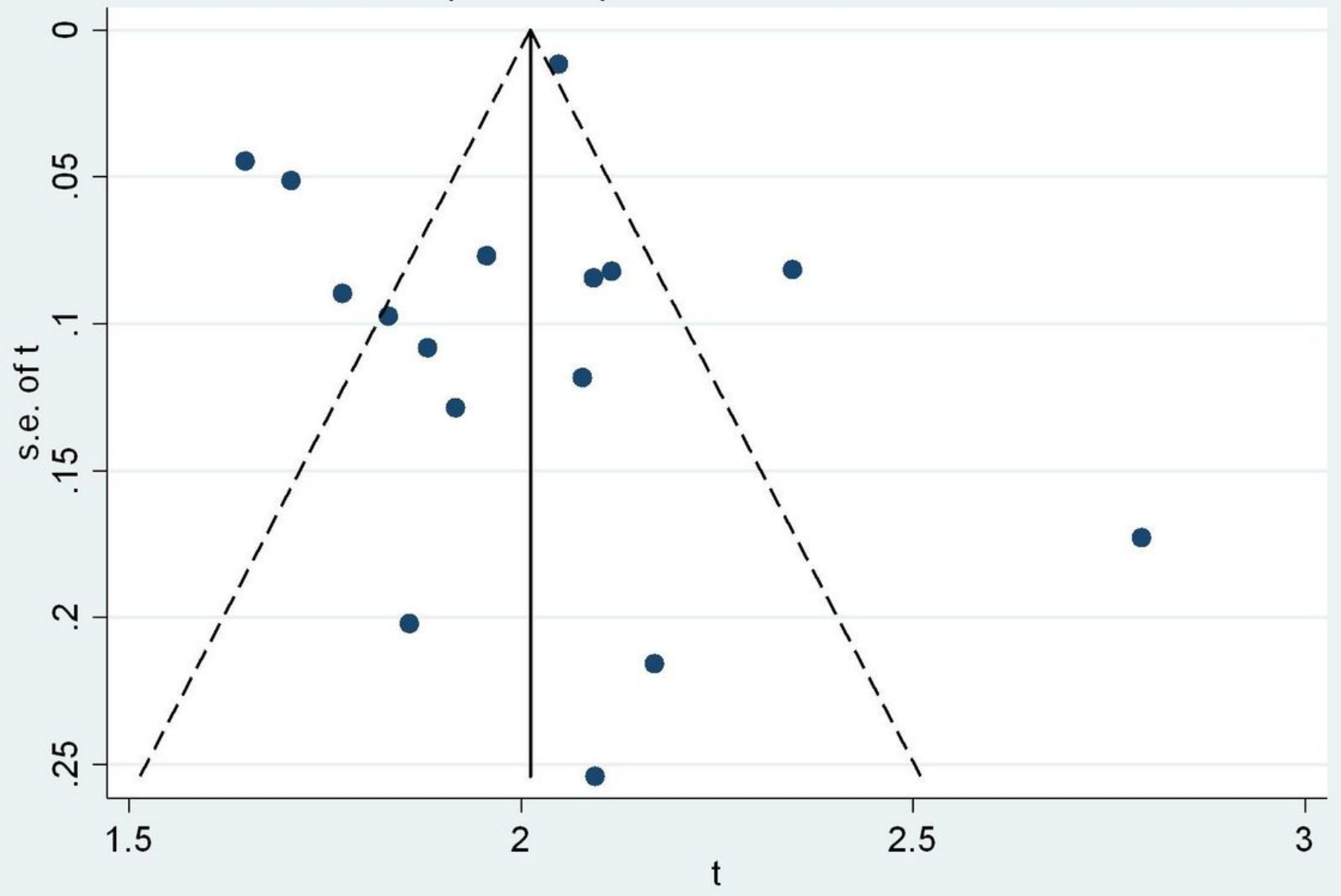

\section{Figure 4}

Meta funnel representation of prevalence estimate of MDR-TB among previously treated TB cases in East Africa, 2007 to 2019. Abbreviation: $t$ : arcsine transformed prevalence estimate of MDR-TB among new diagnosed TB cases and se of $t$, standard error of $t$. 
Study

ID
ES $(95 \% \mathrm{Cl})$
$\%$

Weight
Admassu,2011

Mekonnen et al., 2015

Berhane et al., 2017

Biresaw et al., 2018

Girum et al., 2018

Kerubo et al., 2016

Huerga et al., 2017

Umubyeyi et al., 2007

Eldin et al., 2011

Sabeel et al., 2017

Eldirdery et al., 2017

Chonde et al., 2010

Range et al., 2012

Lukoye et al., 2011

Lukoye, 2013

Okethwangu et al., 2019

Overall $(\mathrm{I}$-squared $=99.1 \%, \mathrm{p}=0.000$ )

NOTE: Weights are from random effects analysis

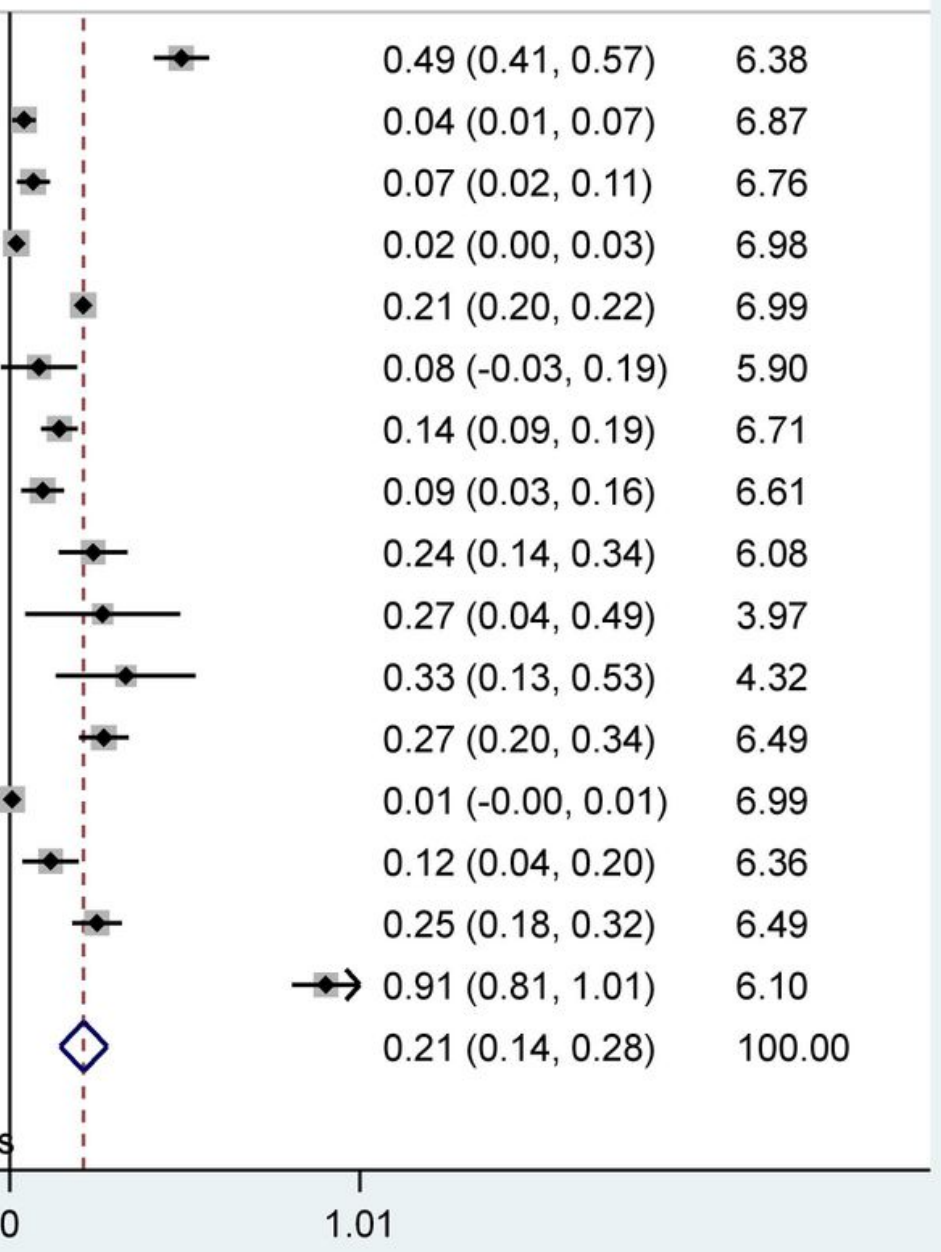

\section{Figure 5}

Forest plot showing the prevalence of MDR-TB among previously treated TB cases in East Africa, 2007 to 2019. Abbreviation: ES: Effect size; Cl: Confidence interval. 